LETTER TO THE EDITOR

\title{
Etomidate in the emergency management of hypercortisolemia
}

\author{
Lip Min Soh ${ }^{1}$, Kirun Gunganah ${ }^{1}$, Scott A Akker ${ }^{1}$, Philip Jones ${ }^{2}$, Hasanin Khachi ${ }^{3}$, Kumbirai Dodzo ${ }^{1}$ \\ and William M Drake ${ }^{1}$ \\ ${ }^{1}$ Department of Endocrinology, ${ }^{2}$ Anaesthetics and Intensive Care and ${ }^{3}$ Pharmacy, St Bartholomew's Hospital, West Smithfield, London EC1A 7BE, UK \\ (Correspondence should be addressed to W M Drake; Email: w.m.drake@qmul.ac.uk)
}

\begin{abstract}
We describe a protocol for etomidate infusion for the emergency management of hypercortisolemia. Etomidate is commenced at $2.5 \mathrm{mg} / \mathrm{h}$ and titrated subsequently according to cortisol levels. It is well tolerated without any sedative effects and can be administered safely via peripheral access for use in the general ward setting.
\end{abstract}

European Journal of Endocrinology 167 727-728

We read with interest the recent paper by Preda et al. (1) in which i.v. etomidate infusion for the management of Cushing's syndrome was reviewed. The authors advocate its use in an intensive care unit (ICU) to ensure that adrenal insufficiency does not occur. While we agree that etomidate is a vital tool in the management of patients in hypercortisolemic crises, its use need not be confined to the ICU.

The pharmacokinetic properties of etomidate are well documented by Van Hamme et al. (2), and there is a clear dissociation between the higher anaesthetic dose and lower doses, which inhibit adrenal function (3). In clinical studies, this has been demonstrated by Schulte et al. (4), where varying doses of etomidate infusion at $0.03,0.1$ and $0.3 \mathrm{mg} / \mathrm{kg}$ per $\mathrm{h}$ showed prominent sedation only at the highest dose. Allolio et al. (5) corroborated this in subjects with Cushing's syndrome, where low-dose etomidate infusion at $2.5 \mathrm{mg} / \mathrm{h}$ decreased mean cortisols to $53 \%$ in $7 \mathrm{~h}$ without any sedative complications.

Against this background, appropriate selection of etomidate dose will minimise any risk of unwanted sedation. We have recently established a protocol for the treatment of Cushing's syndrome in the general ward. Its creation was driven by necessity, as the availability of critical care beds is often limited (6), with priority naturally given to patients who require ventilatory or inotropic support. This protocol was derived following close liaison between clinical endocrinologists, ICU physicians, pharmacists and nursing staff.

In our institution, etomidate is available in a lipid emulsion, as Etomidate-Lipuro. It is given undiluted via a syringe driver, and the preparation is changed every $24 \mathrm{~h}$. The choice of this preparation circumvents the side effects of hemolysis (7), lactic acidosis and nephrotoxicity (8) associated with propylene glycol. It is also better tolerated with minimal thrombophlebitis and pain $(9,10)$ and hence can be administered via a peripheral line, thereby avoiding the potential hazards of central venous cannulation. We use a starting dose of $2.5 \mathrm{mg} / \mathrm{h}$ irrespective of body weight, which is titrated according to cortisol levels, up to a maximum of $4 \mathrm{mg} / \mathrm{h}$.

Cortisol levels are taken at baseline, $4 \mathrm{~h}$ after commencing etomidate, or after each dose titration. Measurement is continued 4 hourly until stable, whereupon the frequency of monitoring may be adjusted. Half hourly observations (blood pressure, heart rate, oxygen saturation and neuro-observations) are taken in the first $2 \mathrm{~h}$, then hourly for the next $4 \mathrm{~h}$, and 4 hourly thereafter. The hypnotic effect of etomidate is enhanced by neuroleptics, opioids, sedatives and alcohol, and concurrent use of these agents should be avoided.

Since implementing the protocol, four patients with severe hypercortisolism from Cushing's disease have received etomidate in the general ward. None required doses above $3 \mathrm{mg} / \mathrm{h}$ to maintain eucortisolemia. When cortisol levels fall $<200 \mathrm{nmol} / \mathrm{l}$, 'add back' therapy of hydrocortisone was given as a form of 'block and replace' regimen. Our patients received etomidate infusion for a mean of 8.2 (range 2.8-12) days, which was well tolerated, with no neurological or gastrointestinal side effects.

We endorse the views expressed by Preda et al. regarding the clinical use of etomidate in the emergency treatment of Cushing's syndrome and hope that our report on its use outside the ICU will prove useful to endocrine colleagues faced with the same clinical scenario.

\section{Declaration of interest}

The authors declare that there is no conflict of interest that could be perceived as prejudicing the impartiality of the research reported. 


\section{Funding}

This research did not receive any specific grant from any funding agency in the public, commercial or not-for-profit sector.

\section{References}

1 Preda VA, Sen J, Karavitaki N \& Grossman AB. Therapy in endocrine disease: etomidate in the management of hypercortisolaemia in Cushing's syndrome: a review. European Journal of Endocrinology 2012167 137-143. (doi:10.1530/EJE-12-0274)

2 Van Hamme MJ, Ghoneim MM \& Ambre JJ. Pharmacokinetics of etomidate, a new intravenous anesthetic. Anesthesiology 197849 274-277. (doi:10.1097/00000542-197810000-00 010)

3 Forman SA. Clinical and molecular pharmacology of etomidate. Anesthesiology $2011 \mathbf{1 1 4}$ 695-707. (doi:10.1097/ALN.0b013e 3181ff72b5)

4 Schulte HM, Benker G, Reinwein D, Sippell WG \& Allolio B. Infusion of low dose etomidate: correction of hypercortisolemia in patients with Cushing's syndrome and dose-response relationship in normal subjects. Journal of Clinical Endocrinology and Metabolism 199070 1426-1430. (doi:10.1210/jcem-705-1426)
5 Allolio B, Schulte HM, Kaulen D, Reincke M, Jaursch-Hancke C \& Winkelmann W. Nonhypnotic low-dose etomidate for rapid correction of hypercortisolaemia in Cushing's syndrome. Klinische Wochenschrift 198866 361-364. (doi:10.1007/BF01735795)

6 Adhikari NK, Fowler RA, Bhagwanjee S \& Rubenfeld GD. Critical care and the global burden of critical illness in adults. Lancet 2010 376 1339-1346. (doi:10.1016/S0140-6736(10)60446-1)

7 Doenicke A, Roizen MF, Hoernecke R, Mayer M, Ostwald P \& Foss J. Haemolysis after etomidate: comparison of propylene glycol and lipid formulations. British Journal of Anaesthesia $1997 \mathbf{7 9}$ 386-388. (doi:10.1093/bja/79.3.386)

8 Bedichek E \& Kirschbaum B. A case of propylene glycol toxic reaction associated with etomidate infusion. Archives of Internal Medicine 1991151 2297-2298. (doi:10.1001/archinte.1991. $00400110137026)$

9 Kulka PJ, Bremer F \& Schuttler J. Anesthesia induction using etomidate in a lipid emulsion. Der Anaesthesist 199342 205-209.

10 Doenicke A, Kugler A, Vollmann N, Suttmann H \& Taeger K. Etomidate using a new solubilizer. Experimental clinical studies on venous tolerance and bioavailability. Der Anaesthesia 199039 475-480.

Received 13 August 2012

Accepted 28 August 2012 